\title{
Volatile Flavor Compounds of Boiled Buckwheat Flour
}

\author{
Izumi Yajima, Tetsuya YanaI, Mikio NaKamura, \\ Hidemasa SaKakibara, Haruyuki UChIDA and Kazuo Hayashi \\ Kawasaki Research Laboratories, T. Hasegawa Co. Ltd., \\ 335-Kariyado, Nakahara-ku, Kawasaki 211, Japan
}

Received August 9, 1982

\begin{abstract}
Volatile flavor compounds of boiled buckwheat flour were collected using a Likens and Nickerson apparatus type and were fractionated into acidic, weak acidic, basic and neutral fractions. The neutral fraction was further fractionated by silica gel column chromatography. All fractions were analyzed by gas chromatography and gas chromatography-mass spectrometry.

Two hundred and nine compounds were thus identified. Among them, 168 were newly identified as volatile flavor compounds of buckwheat flour; special note is made of 2-(1'ethoxyethyl)pyrazine and 2-(1'-ethoxyethyl)-5-methylpyrazine being found which are compounds previously unreported in any literature.
\end{abstract}

Buckwheat noodles, made from buckwheat (Fagopyrum esculentum Moench) flour have a characteristic flavor and pleasant mouth feel differing from other wheat noodles. Generally it is known that the flavor of boiled buckwheat flour has great influence upon the making of appetizing buckwheat foods and their acceptability. Accordingly, we considered it important to clarify the flavor components of boiled buckwheat flour, which have hitherto been insufficiently reported through a few papers, ${ }^{1,2)}$ and have analyzed the volatile flavor components in more detail.

\section{MATERIALS AND METHODS}

Materials. Buckwheat seeds, harvested in Gunma prefecture in Japan, were immediatery used after hulling and milling.

\section{Methods.}

a) Collection of volatile flavor components. The volatile flavor compounds of boiled buckwheat flour were collected using a Likens and Nickerson type of apparatus. A mixture of $500 \mathrm{~g}$ of buckwheat flour and $3 \mathrm{~kg}$ of water was placed in a 5 liter round bottomed-flask. The flask, the mouth of which was left open, was subjected to a 20 minute boil, which initially eliminated the green odor of the freshly milled buckwheat flour and obtained the characteristic boiled aroma. This flask was then connected to the Likens and Nickerson apparatus with a $50 \mathrm{ml}$ round-bottomed flask containing $30 \mathrm{ml}$ of redistilled ethyl ether. Both flasks were brought to the boil and the volatile flavor compounds were simultaneously steam distilled and extracted with diethyl ether. This process was repeated 180 times and the resulting extract batches were combined and concentrated, giving $1.8 \mathrm{~g}$ of flavor concentrate.

b) Fractionation of flavor concentrate. As shown in Fig. 1, the flavor concentrate obtained above was separated into acidic, weak acidic, basic and neutral fractions, which were concentrated to approximately $2 \mathrm{ml}, 0.1 \mathrm{ml}$, $0.1 \mathrm{ml}$ and $0.5 \mathrm{ml}$, respectively. The acidic, weak acidic and basic fractions were analyzed by gas chromatography (GC) and gas chromatography-mass spectrometry (GCMS), the acidic fraction being analyzed after methylation. The remaining neutral fraction was further fractionated into seven fractions by the following method.

c) Fractionation of neutral fraction. The neutral fraction was subjected to successive column chromatography, using a $10 \mathrm{~mm}$ i.d. $\times 200 \mathrm{~mm}$ column packed with silica gel (Wacogel C-200). This was eluted successively with the following solvent systems $(\mathrm{v} / \mathrm{v})$; pentane, pentane-ethyl ether (97:3), pentane-ethyl ether $(95: 5)$, pentane-ethyl ether $(90: 10)$, pentane-ethyl ether $(80: 20)$, ethyl ether and methanol. The volume of each solvent system used was $50 \mathrm{ml}$. Each eluted fraction was concentrated to approximately $0.1 \mathrm{ml}$ and analyzed by GC and GC-MS. Identification of the flavor compounds was made by comparing and matching the mass spectra and GC retention times of the isolated compounds with those of authentic compounds.

d) Conditions of GC. A Hitachi Model 163 gas chromatograph with a flame ionization detector (FID) and a $0.5 \mathrm{~mm}$ i.d. $\times 100 \mathrm{~m}$ glass SCOT column coated with PEG $20 \mathrm{M}$ was used. The column temperature was programmed 


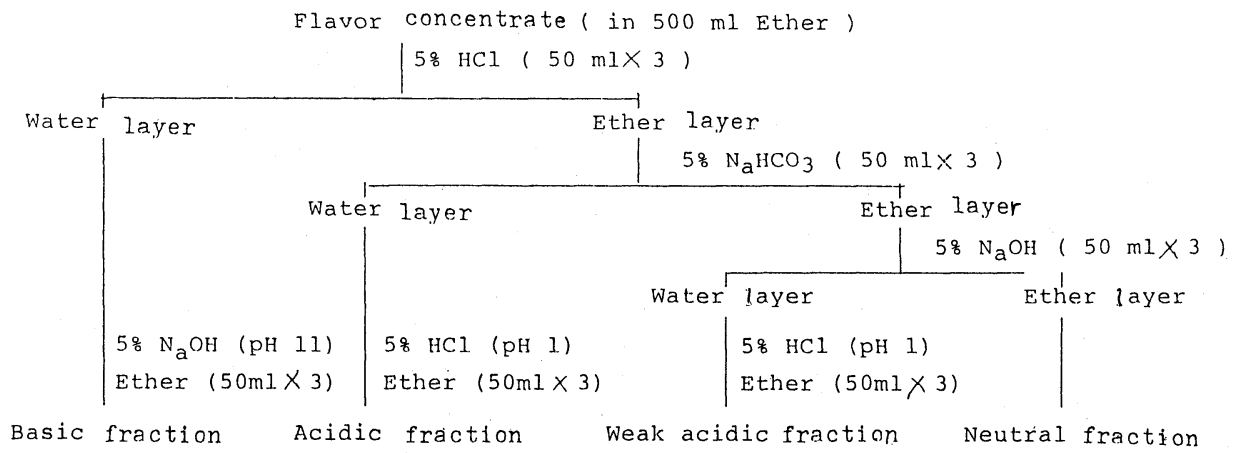

FIG. 1. Fractionation of the Flavor Concentrate of Boiled Buckwheat Flour.

from $60^{\circ} \mathrm{C}$ to $190^{\circ} \mathrm{C}$ at a rate of $3^{\circ} \mathrm{C} / \mathrm{min}$, and the flow rate of nitrogen carrier gas was $1 \mathrm{ml} / \mathrm{min}$.

e) Conditions of GC-MS. A Hitachi Model RMU6MG mass spectrometer was used. A glass SCOT column $(0.28 \mathrm{~mm}$ i.d. $\times 50 \mathrm{~m})$ coated with PEG $20 \mathrm{M}$ was used. Other operating conditions were; column temperature, programmed from $50^{\circ} \mathrm{C}$ to $170^{\circ} \mathrm{C}$ at $2^{\circ} \mathrm{C} / \mathrm{min}$; carrier gas, helium; ionizing voltage, $70 \mathrm{eV}$; accelerating voltage, $3200 \mathrm{~V}$; ion source temperature, $200^{\circ} \mathrm{C}$.

f) Sniffing evaluation of flavor compounds emitted at each peak on the gas chromatograms. The organoleptic evaluation was accomplished by sniffing at the exit port of a Hitachi Model 163 gas chromatograph fitted with an effluent splitter during the elution of samples. The effluent was proportioned by the splitter in a ratio of 1 to 10 , the first portion being passed to the FID circuit and the second portion to the exit port, which was heated to $180^{\circ} \mathrm{C}$ by a small heater to prevent condensation. The gas chromatograph was equipped with a $0.5 \mathrm{~mm}$ i.d. $\times 70 \mathrm{~m}$ glass SCOT column coated with PEG 20M. The other operating conditions were the same as mentioned above.

g) Syntheses of 2-(1'-ethoxyethyl)pyrazine and 2-(1'ethoxyethyl)-5-methylpyrazine.

i) 2-(1'-ethoxyethyl)pyrazine.

2-Ethylpyrazine $(10.8 \mathrm{~g})$ was added to a mixture of NBS $(19.6 \mathrm{~g})$ and benzoyl peroxide $(2.0 \mathrm{~g})$ in $\mathrm{CCl}_{4}(200 \mathrm{ml})$ at room temperature, and the mixture was refluxed $\left(75^{\circ} \mathrm{C}\right)$ for $3 \mathrm{hr}$. The mixture was then filtered and the filtrate concentrated in vacuo to give crude 2 -(1'-bromoethyl)pyrazine $(25 \mathrm{~g})$. The crude bromopyrazine $(25 \mathrm{~g})$ was added to a solution of $\mathrm{NaOH}(8.0 \mathrm{~g})$ in $\mathrm{H}_{2} \mathrm{O}(150 \mathrm{ml}) / \mathrm{EtOH}(150 \mathrm{ml})$ and the mixture was stirred for $5 \mathrm{hr}$ at $35 \sim 38^{\circ} \mathrm{C}$. The mixture was extracted with diethyl ether and the ethereal extract was washed with brine and dried over anhydrous $\mathrm{MgSO}_{4}$. After removal of the solvent, the residue was distilled to give 2 -(1'-ethoxyethyl) pyrazine. $(3.1 \mathrm{~g}, 20 \%$ yield, bp $81 \sim 83^{\circ} \mathrm{C} / 12$ torr $)$.

MS $m / z ; 152\left(\mathbf{M}^{+} 2\right), 109$ (26), 108 (100), 107 (52), 79

(18), 73 (13), 53 (26), 52 (29), 45 (95).

IR $\mathrm{cm}^{-1} ; 2880,1535,1400,1110,1020,940,850$.

NMR $\delta_{\mathrm{TMS}}^{\mathrm{CDCl}_{3}} ; 1.20(3 \mathrm{H}, \mathrm{t}, J=6.5 \mathrm{~Hz}), 1.48(3 \mathrm{H}, \mathrm{d}, J=$ $6.5 \mathrm{~Hz}), 3.47(2 \mathrm{H}, \mathrm{q}, J=6.5 \mathrm{~Hz}), 4.56(1 \mathrm{H}, \mathrm{q}, J=$
TABle I. Yields of Flavor Compounds OBTAINED FROM BOILED BUCKWHEAT Flour

\begin{tabular}{llc}
\hline & Total & $\begin{array}{c}\text { Total flavor } \\
\text { compounds other } \\
\text { than } \mathrm{C}_{14} \sim \mathrm{C}_{18} \\
\text { fatty acids }\end{array}$ \\
\hline Flavor & $1800 \mathrm{mg}^{*}$ & $390 \mathrm{mg}^{*}$ \\
$\quad$ concentrate & $(20 \mathrm{ppm})$ & $(4 \mathrm{ppm})$ \\
\hline Acidic Fr. & & $1 \mathrm{wt} \%$ \\
Weak acidic Fr. & 5 \\
Basic Fr. & 1 \\
Neutral Fr. & 93 \\
\hline
\end{tabular}

* Yield was calculated using the following equation. Yield $(\mathrm{mg})=$ weight $(\mathrm{mg})$

$\frac{100-\text { (solvent peak area } \% \text { on gas chromatogram.) }}{100}$

$6.5 \mathrm{~Hz}), 8.46(2 \mathrm{H}, \mathrm{s}), 8.72(1 \mathrm{H}, \mathrm{s})$.

ii) 2-(1'-ethoxyethyl)-5-methylpyrazine. In the same manner as described above, bromination of 2-ethyl-5methylpyrazine $(18.3 \mathrm{~g}$ ) with NBS $(32 \mathrm{~g})$, and treatment with a solution $\mathrm{NaOH}(12 \mathrm{~g})$ in $\mathrm{H}_{2} \mathrm{O}(150 \mathrm{ml}) / \mathrm{EtOH}$ $(150 \mathrm{ml})$ gave 2-(1'-ethoxyethyl)-5-methylpyrazine. $(5.3 \mathrm{~g}$, $21 \%$ yield, bp $106 \sim 108^{\circ} \mathrm{C} / 16$ torr).

MS $m / z ; 166\left(\mathrm{M}^{+} 1\right), 123$ (30), 122 (100), 121 (55), 93

(15), 73 (13), 53 (17), 51 (17), 45 (92), 39 (36).

IR $\mathrm{cm}^{-1} ; 2880,1480,1340,1110,1035,940,900$.

NMR $\delta_{\mathrm{TMS}}^{\mathrm{CDCl}_{3}} ; 1.23(3 \mathrm{H}, \mathrm{t}, J=6.5 \mathrm{~Hz}), 1.52(3 \mathrm{H}, \mathrm{d}, J=$ $6.5 \mathrm{~Hz}), 2.56(3 \mathrm{H}, \mathrm{s}), 3.51(2 \mathrm{H}, \mathrm{q}, J=6.5 \mathrm{~Hz}), 4.58$ $(1 \mathrm{H}, \mathrm{q}, J=6.5 \mathrm{~Hz}), 8.40(1 \mathrm{H}, \mathrm{s}), 8.62(1 \mathrm{H}, \mathrm{s})$.

\section{RESULTS AND DISCUSSION}

Table I shows the yield of flavor concentrates and each fraction. The yield of flavor concentrates was $1800 \mathrm{mg}$, and this was found to contain large amounts of $\mathrm{C} 14 \sim \mathrm{C} 18$ higher 

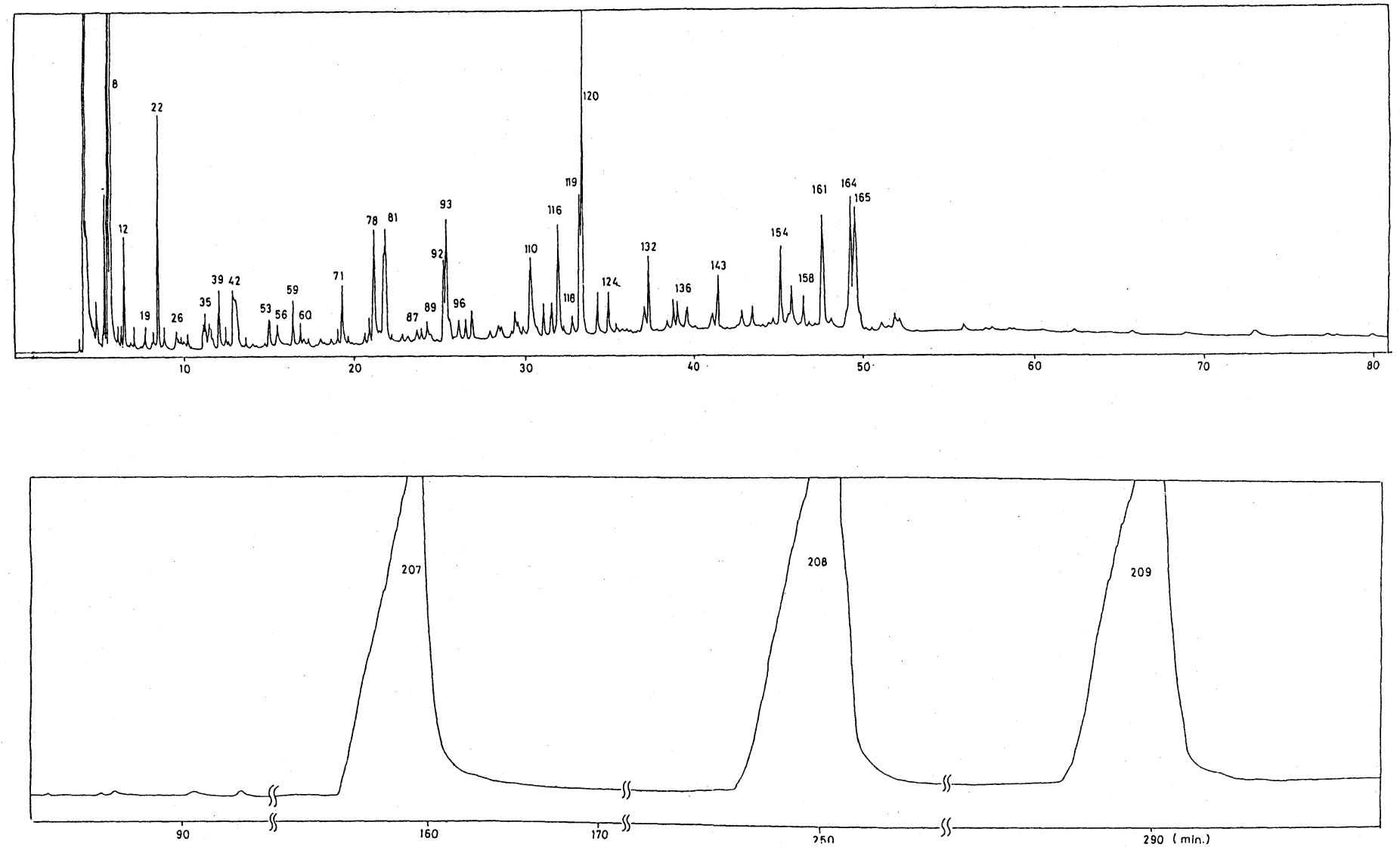

Fig. 2. Gas Chromatogram of the Flavor Concentrate of Boiled Buckwheat Flour. 
fatty acids which are not necessarily important to the characteristic aroma of boiled backwheat flour. The yield of total flavor compounds, other than these fatty acids, was $390 \mathrm{mg}$ which is equivalent to only $4.3 \mathrm{ppm}$ of the weight of the raw material used.

As can be seen from Table I, the neutral compounds amounted to more than $90 \%$ of the total flavor compounds and, therefore, the aroma of boiled buckwheat flour is seen to be made up mainly of hydrocarbons and neutral oxygenated compounds such as alcohols, aldehydes, ketones, esters, ethers, etc.

Figure 2 shows a gas chromatogram of the flavor concentrate of boiled buckwheat flour. The chromatogram indicates the presence of over 200 compounds.

Although the flavor concentrate had the characteristic aroma of boiled buckwheat flour, no characteristic specific aroma compounds could be detected by sniffing at the exit port of the gas chromatograph.

\section{1) Acidic and weak acidic fractions}

The acidic fraction, from which $\mathrm{C} 2 \sim \mathrm{C} 9$ aliphatic carboxylic acids were identified, had a pungent, acidic odor. But it seems that this acidic fraction is not very important to the characteristic aroma of boiled buckwheat flour.

On the other hand, the weak acidic fraction had a smoky or phenolic odor and eight phenolic compounds such as phenol, guaiacol, 4-vinylphenol and salicylaldehyde were identified from this fraction. Among these phenolic compounds, salicylaldehyde was the major component. Aoki, et al. have reported that salicylaldehyde existed in large quantities in roller-milled buckwheat flour consisting mainly of the pericarp, which also has been confirmed by our previous experiments on the pericarp of buckwheat. Salicylaldehyde is seen to be an important flavor component of the pericarp and to contribute to the aroma of the pericarp rather than that of boiled buckwheat flour.

\section{2) Basic fraction}

The basic fraction had a nutty and slightly fish-like odor.

Figure 3 shows a gas chromatogram of the basic fraction. The compounds corresponding to peak no. 97 and peak no. 105 had pleasant nutty aromas.

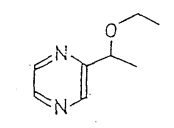

Peak no. 97

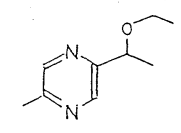

Peak no. 105
Mass spectra indicated that these compounds were probably 2-(1'-ethoxyethyl)pyrazine and 2-(1'-ethoxyethyl)-5-methyl pyrazine, respectively.

Further confirmation was made by comparing and matching the spectra and GC retention times of these compounds with those of authentic compounds synthesized in our laboratory. IR, MS and NMR data of these two synthesized pyrazines are shown in the experiment (g). These two pyrazine derivatives were newly identified here from buckwheat flour and had not been reported in any literature.

In addition, other pyrazines and pyridines such as 2-methylpyrazine, 2-ethylpyrazine, tetramethylpyrazine, 2-methylpyridine and 2,6-dimethylpyridine were identified from the basic fraction. Most of these compounds are thought to have been formed by the Maillard reaction. It seems that the nutty aroma of the basic fraction is due to the pyrazines, with the fish-like odor being due to the pyridines.

\section{3) Neutral fraction}

The neutral fraction had a characteristic aroma of boiled buckwheat flour, but with a somewhat green odor.

The gas chromatogram of the neutral fraction is shown in Fig. 4. In order to facilitate analysis of the various minor components, the neutral fraction was further fractionated into seven fractions, using successive silica gel column chromatography. The first fraction consisted of hydrocarbons and the second consisted of mainly BHT, which was thought to be 


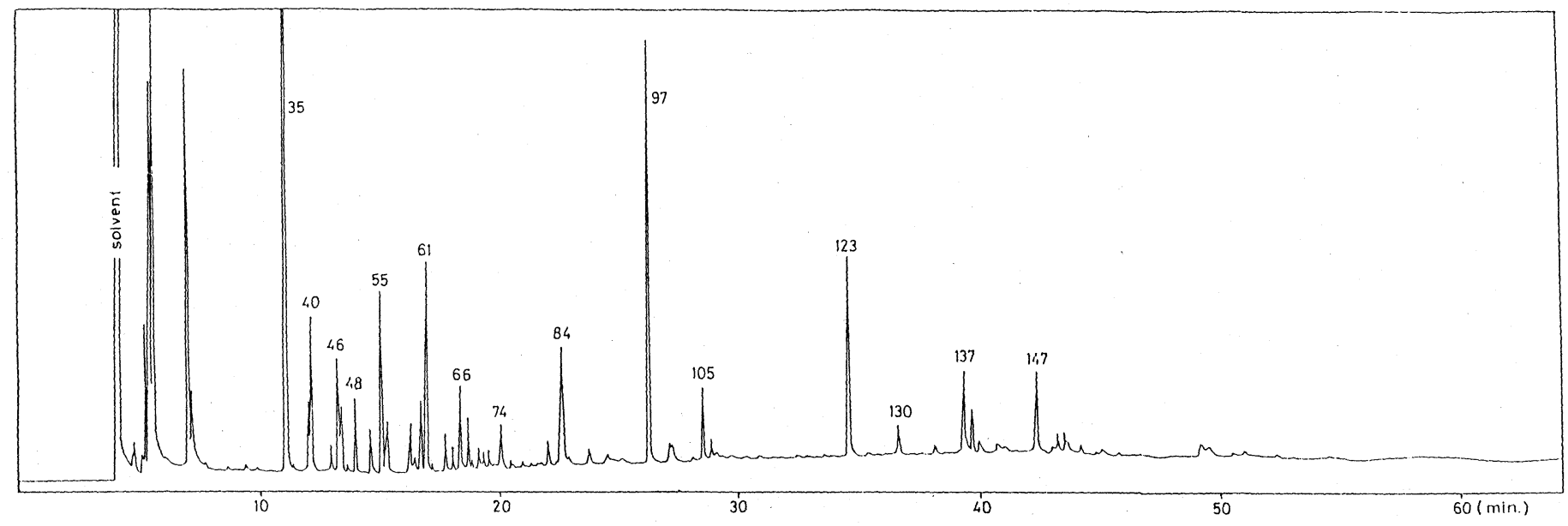

Fig. 3. Gas Chromatogram of the Basic Fraction of Boiled Buckwheat Flour. 


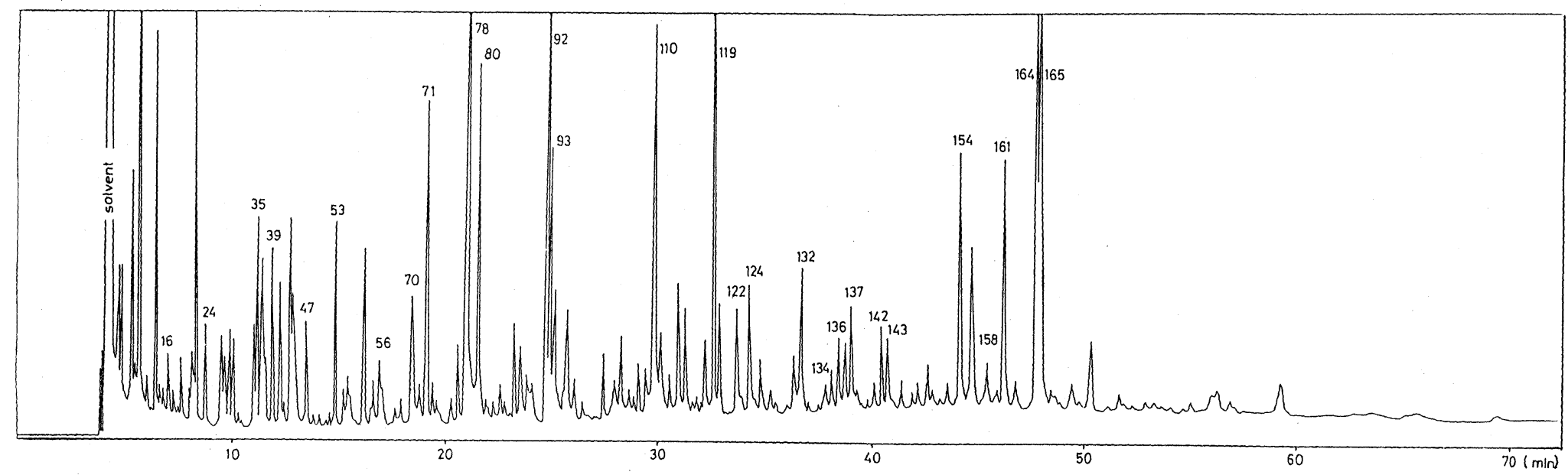

2

Fig. 4. Gas Chromatogram of the Neutral Fraction of Boiled Buckwheat Flour. 


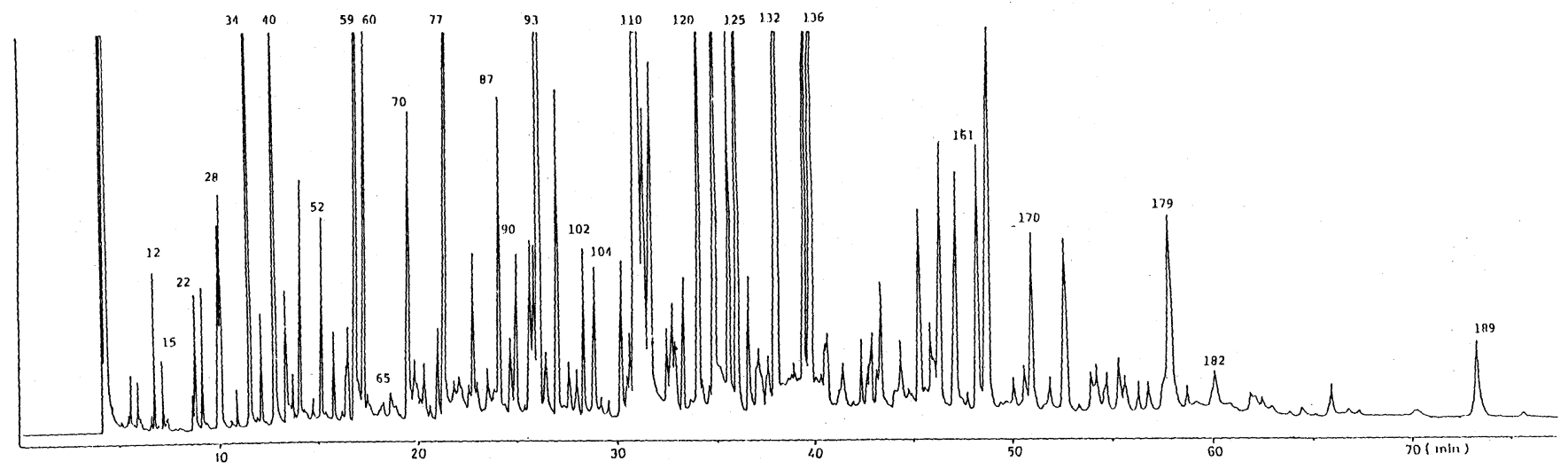

FIG. 5. Gas Chromatogram of the Fourth Fraction Obtained from the Neutral Fraction by Column Chromatography. 
Table II. Volatile Flavor Compounds Identified FROM BOILED BUCKWHEAT FLOUR

\begin{tabular}{|c|c|c|c|}
\hline Peak no. & Compounds & Peak no. & Compounds \\
\hline & Hydrocarbons & 110 & 1-Nonanol \\
\hline $1^{*}$ & Octane & $124^{*}$ & 1-Decanol \\
\hline $6^{*}$ & Nonane & $129^{*}$ & Nerol \\
\hline $13 *$ & Decane & $133^{*}$ & Geraniol \\
\hline $17 *$ & $\alpha$-Pinene & 137 & Benzyl alcohol \\
\hline 19 & Toluene & 142 & Phenethyl alcohol \\
\hline $22 *$ & Camphene & & Aldehydes \\
\hline 24 & Undecane & $8^{*}$ & 3-Methylbutanal \\
\hline $27 *$ & $\beta$-Pinene & 12 & Pentanal \\
\hline $28 *$ & Sabinene & 22 & Hexanal \\
\hline 30 & Ethylbenzene & $24^{*}$ & (E)-2-Methyl-2-butenal \\
\hline $32 *$ & Myrcene & $35^{*}$ & Heptanal \\
\hline $39 *$ & Limonene & $38^{*}$ & (E)-2-Pentenal \\
\hline $48^{*}$ & Styrene & $40^{*}$ & (E)-2-Hexenal \\
\hline $51^{*}$ & $p$-Cymene & 53 & Octanal \\
\hline $56^{*}$ & Tridecane & $59 *$ & (E)-2-Heptenal \\
\hline $59 *$ & 2,2,6-Trimethylcyclohexane & $65^{*}$ & 2,4-Hexadienal \\
\hline 67 & Tetradecane & 71 & Nonanal \\
\hline $86^{*}$ & $\alpha$-p-Dimethylstyrene & $77^{*}$ & (E)-2-Octenal \\
\hline 90 & Pentadecane & $87 *$ & 2,4-Heptadienal \\
\hline 107 & Hexadecane & 88 & Decanal \\
\hline $107^{*}$ & $\beta$-Elemene & 92 & Benzaldehyde \\
\hline 121 & Heptadecane & $93^{*}$ & (E)-2-Nonenal \\
\hline 124 & Naphthalene & $102 *$ & 2,4-Octadienal \\
\hline 137 & Octadecane & $102 *$ & 2,6-Nonadienal \\
\hline $140^{*}$ & Calamenene & $105^{*}$ & Undecanal \\
\hline $142 *$ & 1-Methylnaphthalene & $108^{*}$ & $\beta$-Cyclocitral \\
\hline $151^{*}$ & 2-Methylnaphthalene & 110 & $(E)$-2-Decenal \\
\hline $155^{*}$ & Nonadecane & $111^{*}$ & Phenylacetaldehyde \\
\hline $164^{*}$ & Diphenyl & $118^{*}$ & 2,4 -Nonadienal \\
\hline $168^{*}$ & Eicosane & $120 *$ & Dodecanal \\
\hline $175^{*}$ & Heneicosane & 120 & Salicylaldehyde \\
\hline $180^{*}$ & Docosane & $125^{*}$ & $(E)-2,(Z)$-4-Decadienal \\
\hline $184^{*}$ & Tricosane & $132 *$ & $(E)-2,(E)$-4-Decadienal \\
\hline $187^{*}$ & Tetracosane & $134^{*}$ & Tridecanal \\
\hline $189^{*}$ & Pentacosane & $140^{*}$ & Cinnamic aldehyde \\
\hline $190^{*}$ & Hexacosane & $145^{*}$ & 2,4-Undecadienal \\
\hline $195^{*}$ & Heptacosane & $146^{*}$ & 2-Phenyl-2-butenal \\
\hline & Alcohols & $149^{*}$ & Anisaldehyde \\
\hline $8^{*}$ & Ethanol & & Ketones \\
\hline $18^{*}$ & 1-Propanol & 12 & 2-Pentanone \\
\hline $21^{*}$ & 2-Methylpropanol & $15^{*}$ & 4-Methyl-2-pentanone \\
\hline 26 & 1-Butanol & $22 *$ & 2-Hexanone \\
\hline $28^{*}$ & 1-Penten-3-ol & $25^{*}$ & 3-Penten-2-one \\
\hline 36 & 3-Methylbutanol & $28^{*}$ & 4-Methyl-3-penten-2-one \\
\hline 43 & 1-Pentanol & 34 & 2-Heptanone \\
\hline $56^{*}$ & 2-Heptanol & $43^{*}$ & 6-Methyl-2-heptanone \\
\hline 61 & 1-Hexanol & $47 *$ & 3-Octanone \\
\hline $67^{*}$ & 3-Octanol & 52 & 2-Octanone \\
\hline $78^{*}$ & 1-Octen-3-ol & $55^{*}$ & 1-Octen-3-one \\
\hline $80^{*}$ & 6-Methyl-5-hepten-2-ol & $55^{*}$ & Cyclohexanone \\
\hline 85 & 2-Ethylhexanol & $60^{*}$ & 6-Methyl-5-hepten-2-one \\
\hline $89^{*}$ & 2-Nonanol & $64^{*}$ & 3,3-Dimethylcyclohexanone \\
\hline 92 & Linalool & 70 & 2-Nonanone \\
\hline 96 & 1-Octanol & $73^{*}$ & Isophorone \\
\hline $104^{*}$ & 4-Terpineol & $82^{*}$ & Menthone \\
\hline
\end{tabular}


TABLE II. (continued)

\begin{tabular}{|c|c|c|c|}
\hline Peak no. & Compounds & Peak no. & Compounds \\
\hline $87 *$ & 2-Decanone & $*$ & Eicosanyl acetate \\
\hline 90 & Camphor & $*$ & Benzyl salicylate \\
\hline 104 & 2-Undecanone & & Lactones \\
\hline $118^{*}$ & 6,10-Dimethylundecan-2-one & $145^{*}$ & 4-Octanolide \\
\hline $118^{*}$ & 2,6,6-Trimethyl-2-cyclohexene-1,4-dione & $159 *$ & 4-Nonanolide \\
\hline $126^{*}$ & $p$-Methylacetophenone & $188^{*}$ & Dihydroactinidiolide \\
\hline $136^{*}$ & $\alpha$-Ionone & & Ethers \\
\hline $136^{*}$ & Geranyl acetone & $40 *$ & 1,8-Cineol \\
\hline $142 *$ & $\beta$-Ionone & $79 *$ & $p$-Cresyl methyl ether \\
\hline $154 *$ & $\beta$-Ionone epoxide & $83^{*}$ & Linalool oxide \\
\hline $161^{*}$ & 2-Pentadecanone & $115^{*}$ & 1-Methoxy-4-vinylbenzene \\
\hline $170^{*}$ & $6,10,14$-Trimethylpentadecan-2-one & 120 & 1,2-Dimethoxybenzene \\
\hline $172 *$ & 2-Heptadecanone & $131 *$ & 1,2-Dimethoxy-4-methylbenzene \\
\hline \multirow[t]{2}{*}{$179^{*}$} & Farnesyl acetone & $133^{*}$ & Anethole \\
\hline & Acids & $154^{*}$ & Caryophylene epoxide \\
\hline $78^{*}$ & Acetic acid & $157^{*}$ & Diphenyl oxide \\
\hline $92 *$ & Propionic acid & $158^{*}$ & Methyleugenol \\
\hline $98^{*}$ & 2-Methylpropionic acid & $161^{*}$ & 1,2-Dimethoxy-4-vinylbenzene \\
\hline $116^{*}$ & Butanoic acid & & Phenols \\
\hline $118^{*}$ & 3-Methylbutanoic acid & .136 & Guaiacol \\
\hline $122^{*}$ & Pentanoic acid & 154 & Phenol \\
\hline $134^{*}$ & Hexanoic acid & $154^{*}$ & $o$-Cresol \\
\hline $148 *$ & Heptanoic acid & $164^{*}$ & $p$-Cresol \\
\hline $162 *$ & Octanoic acid & $168^{*}$ & Thymol \\
\hline$*$ & Nonanoic acid & $168 *$ & Eugenol \\
\hline * & Benzoic acid & $184^{*}$ & 4-Vinylphenol \\
\hline$*$ & Myristic acid & & Pyridines \\
\hline$*$ & Pentadecanoic acid & $35^{*}$ & Pyridine \\
\hline $207^{*}$ & Palmitic acid & $40^{*}$ & 2-Methylpyridine \\
\hline$*$ & Oleic acid & $46^{*}$ & 2,6-Dimethylpyridine \\
\hline $208 *$ & Stearic acid & $52 *$ & 2-Ethylpyridine \\
\hline $209 *$ & Linoleic acid & $55^{*}$ & 4-Methylpyridine \\
\hline \multirow[t]{2}{*}{$*$} & Linolenic acid & $103^{*}$ & 2-Acetylpyridine \\
\hline & Esters & & Pyrazines \\
\hline $3^{*}$ & Ethyl formate & $40^{*}$ & Pyrazine \\
\hline 6 & Ethyl acetate & $48^{*}$ & 2-Methylpyrazine \\
\hline 77 & Ethyl octanoate & $60^{*}$ & 2-Ethylpyrazine \\
\hline $102 *$ & Bornyl acetate & $84^{*}$ & Tetramethylpyrazine \\
\hline $109^{*}$ & Methyl geranate & $97^{*}$ & 2-(1'-Ethoxyethyl)pyrazine \\
\hline $118^{*}$ & Terpinyl acetate & $105^{*}$ & 2-(1'-Ethoxyethyl)-5-methylpyrazine \\
\hline $159 *$ & Methyl myristate & & Thiazoles \\
\hline $169^{*}$ & Methyl pentadecanoate & $47^{*}$ & Thiazole \\
\hline $181^{*}$ & Methyl palmitate & $111^{*}$ & 2-Acetylthiazole \\
\hline $183^{*}$ & Isopropyl palmitate & $149^{*}$ & Benzothiazole \\
\hline $184^{*}$ & Ethyl palmitate & & Miscellaneous \\
\hline$*$ & Methyl stearate & $19 *$ & Dimethyl sulfide \\
\hline$*$ & Methyl oleate & 42 & 2-Pentylfuran \\
\hline$*$ & Ethyl stearate & $118^{*}$ & 2-Formylthiophene \\
\hline$*$ & Ethyl oleate & $130^{*}$ & Aniline \\
\hline * & Methyl linolate & $137 *$ & Nicotine \\
\hline * & Octadecyl acetate & 143 & B.H.T \\
\hline$*$ & Ethyl linolate & $147^{*}$ & Cinnamyl nitrile \\
\hline$*$ & Methyl linolenate & $182 *$ & Indole \\
\hline * & Ethyl linolenate & 189 & Dibutyl Phthalate \\
\hline$*$ & Benzyl benzoate & $* 1$ & Diphenylamine \\
\hline
\end{tabular}

* Newly identified. 
a contaminant. The third fraction, having a green odor, consisted mainly of alkanals. The fourth fraction had part of the characteristic aroma of boiled buckwheat flour. Figure 5 shows a gas chromatogram of this fraction. The many peaks indicate the complexity of its composition. From these peaks, 55 compounds, most of which were carbonyl compounds such as alkenals, alkadienals and ketones, were identified. However, none of compounds individually could be claimed to have the characteristic aroma of boiled buckwheat flour by sniffing at the exit port of the gas chromatograph. Therefore, it is thought that the characteristic aroma of the fourth fraction was due to the combined aroma of all the compounds appearing on the gas chromatogram.

1-Octen-3-ol, having a musty odor, was the major compound in the fifth fraction. This has also been identified as one of major flavor components of freshly-milled buckwheat flour in our previous experiments. Thiazoles, having cereal-like aromas, were also identified in this fraction, and seem to contribute in part to the characteristic aroma of boiled buckwheat flour. These thiazoles are considered to have been produced by various reactions of sulfurcontaining amino acids with carbonyl compounds.

Table II lists the compounds that were identified from the flavor concentrate of boiled buckwheat flour. The aldehydes such as alkanals, alkenals and alkadienals, which were the major components in the neutral fraction, are thought to have been formed through the oxidative degradation of lipids and fatty acids and/or the Maillard reaction of various amino acids with carbonyl compounds. In conclusion, 209 compounds were identified from the flavor concentrate of boiled buckwheat flour. Among these, 168 were identified from buckwheat flour for the first time. None of them, however, were found individually to have the characteristic aroma of boiled buckwheat flour. The aroma of boiled buckwheat flour is very complex in its composition and seems to be made up from the combined effect of aromas of the identified and possibly unidentified compounds.

\section{REFERENCES}

1) T. Imai, S. Shibata and H. Kato, Abstracts of Papers, Annual Meeting of the Agricultural Chemical Society of Japan, Tokyo, 1979, p. 115.

2) M. Aoki, N. Koizumi, G. Ogawa and T. Yoshizaki, Nippon Shokuhin Kogyo Gakkaishi, 28, 476 (1981).

3) T. H. Schulz, R. A. Flath, T. R. Mon, S. B. Eggling and R. Teranishi, J. Agric. Food Chem., 25, 446 (1977).

4) F. J. Mulders, Z. Lebensm. Unters.-Forsch., 152, 193 (1973).

5) S. Kato, T. Kurata and M. Fujimaki, Agric. Biol. Chem., 37, 539 (1973). 